\title{
A rapid stability-indicating, fused-core HPLC method for simultaneous determination of $\beta$-artemether and lumefantrine in anti-malarial fixed dose combination products
}

\author{
Sultan Suleman ${ }^{1,2}$, Kirsten Vandercruyssen ${ }^{1}$, Evelien Wynendaele ${ }^{1}$, Matthias D'Hondt', Nathalie Bracke ${ }^{1}$,
} Luc Duchateau $^{3}$, Christian Burvenich ${ }^{3}$, Kathelijne Peremans ${ }^{3}$ and Bart De Spiegeleer ${ }^{1 *}$

\begin{abstract}
Background: Artemisinin-based fixed dose combination (FDC) products are recommended by World Health Organization (WHO) as a first-line treatment. However, the current artemisinin FDC products, such as $\beta$-artemether and lumefantrine, are inherently unstable and require controlled distribution and storage conditions, which are not always available in resource-limited settings. Moreover, quality control is hampered by lack of suitable analytical methods. Thus, there is a need for a rapid and simple, but stability-indicating method for the simultaneous assay of $\beta$-artemether and lumefantrine FDC products.

Methods: Three reversed-phase fused-core HPLC columns (Halo RP-Amide, Halo C18 and Halo Phenyl-hexyl), all thermostated at $30^{\circ} \mathrm{C}$, were evaluated. $\beta$-artemether and lumefantrine (unstressed and stressed), and reference-related impurities were injected and chromatographic parameters were assessed. Optimal chromatographic parameters were obtained using Halo RP-Amide column and an isocratic mobile phase composed of acetonitrile and $1 \mathrm{mM}$ phosphate buffer $\mathrm{pH} 3.0(52: 48 ; \mathrm{VN})$ at a flow of $1.0 \mathrm{ml} / \mathrm{min}$ and $3 \mu \mathrm{l}$ injection volume. Quantification was performed at $210 \mathrm{~nm}$ and $335 \mathrm{~nm}$ for $\beta$-artemether and for lumefantrine, respectively. In-silico toxicological evaluation of the related impurities was made using Derek Nexus v2.0 ${ }^{\circledR}$.

Results: Both $\beta$-artemether and lumefantrine were separated from each other as well as from the specified and unspecified related impurities including degradants. A complete chromatographic run only took four minutes. Evaluation of the method, including a Plackett-Burman robustness verification within analytical QbD-principles, and real-life samples showed the method is suitable for quantitative assay purposes of both active pharmaceutical ingredients, with a mean recovery relative standard deviation ( \pm RSD) of $99.7 \%( \pm 0.7 \%)$ for $\beta$-artemether and $99.7 \%( \pm 0.6 \%)$ for lumefantrine. All identified $\beta$-artemether-related impurities were predicted in Derek Nexus $v 2.0^{\circledR}$ to have toxicity risks similar to $\beta$-artemether active pharmaceutical ingredient (API) itself.

Conclusions: A rapid, robust, precise and accurate stability-indicating, quantitative fused-core isocratic HPLC method was developed for simultaneous assay of $\beta$-artemether and lumefantrine. This method can be applied in the routine regulatory quality control of FDC products. The in-silico toxicological investigation using Derek Nexus ${ }^{\circledR}$ indicated that the overall toxicity risk for $\beta$-artemether-related impurities is comparable to that of $\beta$-artemether API.
\end{abstract}

Keywords: Anti-malaria, $\beta$-artemether, Lumefantrine, Stability-indicating assay, HPLC-UV, Fused-core, Finished pharmaceutical product, Quality-by-design (QbD)

\footnotetext{
* Correspondence: Bart.Despiegeleer@UGent.be

'Drug Quality and Registration (DruQuaR) group, Faculty of Pharmaceutical

Sciences, Ghent University, Harelbekestraat 72, Ghent B-9000, Belgium

Full list of author information is available at the end of the article
} 


\section{Background}

Malaria is endemic throughout most of the tropics where approximately three billion people, living in 108 countries, are exposed. Approximately 243 million people annually develop symptomatic malaria [1]. Most of these can be attributed to Plasmodium falciparum, but Plasmodium vivax and Plasmodium knowlesi can also cause severe diseases. An estimated 3.3 billion people were at risk of malaria in 2010 with populations living in subSaharan Africa having the highest risk of acquiring malaria, and children under five years of age and pregnant women being most severely affected [2,3]. Malaria case management remains a vital component of malaria control strategies. This entails early diagnosis and prompt treatment with effective anti-malarial medicines [4]. The World Health Organization (WHO) has recommended that all anti-malarials should consist of a combination of an artemisinin derivative with a co-drug such as lumefantrine, amodiaquine or mefloquine; most malaria endemic countries have now adopted artemisinin-based anti-malarial combination therapy (ACT) as first-line treatment of $P$. falciparum malaria in place of chloroquine, quinine and sulphadoxine-pyrimethamine fixed dose combinations [5]. However, the emergence of resistance is of great concern [6-8], and this problem is fuelled by poor quality anti-malarial drugs.

Poor quality anti-malarials are a severe underrecognized public health problem, reducing the effectiveness of these drugs and threatening current treatment policies [9]. There are three main types of poor quality medicines: substandard, degraded and counterfeit. Substandard drugs are produced with inadequate attention to good manufacturing practices and may have content outside accepted limits. Degraded formulations may result from (unwanted) exposure of initially well produced, good quality medicines to light, heat and humidity $[10,11]$. Therefore, the ultimate purpose of stability testing is to provide evidence on how the quality of a drug varies with time under the influence of a variety of environmental factors such as temperature, humidity and light and enables recommendations of storage conditions, retest periods and shelf life to be established. The two main chemical aspects of the drug product that play an important role in shelf-life determinations are the assay of active drug (efficacy) and degradants generated during the stability study (safety). The assay of drug product in stability test samples obviously needs to be determined using a stabilityindicating method, as recommended by the International Conference on Harmonization (ICH) guidelines [12,13]. Moreover, the intrinsic stability of a finished drug product should also be considered as a possible quality attribute when evaluating and comparing different drug products with the same active pharmaceutical ingredient (API). For example, it has been demonstrated that the half-life of $\beta$-artemether-containing products at $50^{\circ} \mathrm{C}$ can range between 0.70 and 9.52 months [14].

$\beta$-artemether is a methyl ether derivative of artemisinin, which is a peroxide lactone isolated from the Chinese anti-malarial plant Artemisia annua (Figure 1). Chemically, it is (+)-(3-alpha,5a-beta,6-beta,8a-beta,9alpha,12-beta,12aR)-decahydro-10-methoxy-3,6,9-trimethyl3,12-epoxy-12H-pyrano(4,3-j)-1,2-benzodioxepin [15]. Lumefantrine (benflumetol) is a 2,4,7,9-substituted fluorene (2,3-benzindene) derivative (Figure 1). Chemically, it is (9Z)-2,7-dichloro-9-[(4-chlorophenyl)methylene]-a[dibutylamino) methyl]-9H-fluorene-4-methanol [16]. Both compounds are now commercially available in fixed combination products (ACT), which are proven to be highly efficacious for treatment of uncomplicated $P$. falciparum malaria. The increasing use of these $\beta$-artemetherlumefantrine combination anti-malarial products and the intrinsic stability of these products requires controlled storage conditions. However, in resource-limited settings, stability of these products is not guaranteed since the supply chains do not have consistently appropriate temperature and humidity quality assurance systems [17]. Therefore, it is important to have a rapid, but robust and stabilityindicating quantitative method for the simultaneous assay

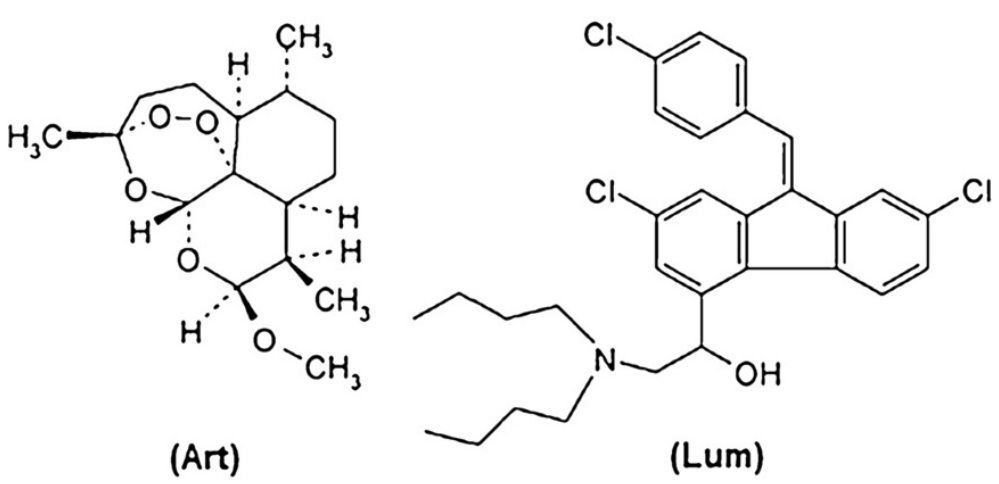

Figure 1 Structure of $\beta$-artemether (Art) and lumefantrine (Lum). 
of $\beta$-artemether and lumefantrine in fixed dose combination (FDC) products.

Currently, there are HPLC methods for the assay of $\beta$-artemether in finished pharmaceutical products (FPP) [18-20], as well as for lumefantrine analysis [21-23]. Only a few HPLC methods were reported for the quantitative determination of $\beta$-artemether and lumefantrine in fixed combination anti-malarial products [24-26]. However, no simple, rapid and proven stability-indicating method has been reported for the simultaneous analysis of both active pharmaceutical drug products. Hence, the present study reports a rapid, economical, precise and accurate method for the assay of $\beta$-artemether and lumefantrine in the presence of their degradants.

\section{Methods}

\section{Samples and chemicals}

$\beta$-artemether and lumefantrine APIs, Co-Artesiane ${ }^{\circledR}$ FPP powder for oral suspension, dihydroartemisinin (DHA), artemisinin, 9,10-anhydroartemisinin (AHA; late eluting impurity (LEI)) and $\alpha$-artemether standards were supplied by Dafra Pharma International (Belgium). Coartem ${ }^{\circledR}$ and Artemine ${ }^{\circledR}$ samples were collected from different markets in Ethiopia. Analytical solutions were prepared using HPLC grade unstabilized tetrahydrofuran (THF) (Fisher Scientific, Leicestershire, UK) obtaining a concentration of $0.2 \mathrm{mg} / \mathrm{ml} \beta$-artemether and $1.2 \mathrm{mg} / \mathrm{ml}$ lumefantrine corresponding to $100 \%$ label claim (lc). Hydrogen peroxide $\left(\mathrm{H}_{2} \mathrm{O}_{2}\right)$ and sodium hydroxide $(\mathrm{NaOH})$ were purchased from Merck (Darmstadt, Germany), hydrochloric acid $(\mathrm{HCl})$ and o-phosphoric acid from Sigma-Aldrich (St Louis, USA). Sartorius (Göttingen, Germany) ultrapure $18.2 \mathrm{~m} \Omega . \mathrm{cm}$ quality water and HPLC grade acetonitrile (Fisher Scientific, UK) were used for HPLC-UV analysis.

\section{Liquid chromatography and analytical conditions}

The HPLC analyses were carried out using HPLC-PDA apparatus consisting of a Waters Alliance 2695 separation module and a Waters 2998 photodiode array detector with Empower 2 software for data acquisition (all Waters, Milford, MA, USA). The following fused-core stationary-phase chemistries were evaluated: (i) Halo RPAmide $(50 \times 4.6 \mathrm{~mm}$ id; $2.7 \mu \mathrm{m}$ particle size); (ii) Halo C18 $(50 \times 4.6 \mathrm{~mm}$ id; $2.7 \mu \mathrm{m}$ particle size); and, (iii) Halo Phenyl-hexyl $(50 \times 4.6 \mathrm{~mm}$ id; $2.7 \mu \mathrm{m}$ particle size), all Achrom (Machelen, Belgium) and all thermostated at $30^{\circ} \mathrm{C}$. Detection was performed from 190-400 $\mathrm{nm}$. Lumefantrine quantification was done at $335 \mathrm{~nm}$, a wavelength at which $\beta$-artemether and its related impurities are not absorbing. For $\beta$-artemether, quantification was performed at $210 \mathrm{~nm}$. As $\mathrm{N}$-oxide-lumefantrine might interfere if present, back-calculating the peak area of $\mathrm{N}$ oxide-lumefantrine using peak area conversion factor from
$335 \mathrm{~nm}$ to $210 \mathrm{~nm}$ (1.64) was performed and the obtained value was subtracted from the peak area at $210 \mathrm{~nm}$. The injection volume was $3 \mu \mathrm{l}$. Isocratic mobile phases containing acetonitrile and $1 \mathrm{mM}$ phosphate buffer $\mathrm{pH} 3.0$ were used at a flow of $1.0 \mathrm{ml} / \mathrm{min}$. The separation of $\beta$-artemether and lumefantrine was evaluated using different proportions of these mobile phase solvents and, for each condition, the retention factor $\left(k^{\prime}\right)$ and asymmetry factor $\left(A_{s}\right)$ were calculated based on the method described in European Pharmacopoeia (Ph. Eur.) 2.2.46 [27] (see Additional file 1). The optimal condition was achieved using the Halo RP-Amide column and a mobile phase composed of acetonitrile and $1 \mathrm{mM}$ phosphate buffer pH $3.0(52: 48 \mathrm{~V} / \mathrm{V})$.

\section{Preparation of solutions}

Preparation of $\beta$-artemether and lumefantrine standard solution

Approximately $20.0 \mathrm{mg} \quad \beta$-artemether and $120.0 \mathrm{mg}$ lumefantrine reference standards were accurately weighed and transferred to a $100.0 \mathrm{ml}$ volumetric flask. Eighty $\mathrm{ml}$ tetrahydrofuran was added to dissolve both compounds and the solution was diluted to volume using mobile phase.

\section{Preparation of test sample solutions}

Four samples of fixed dose combination tablets (Coartem ${ }^{\circledR}$ and Artemine ${ }^{\circledR}$ ) containing $20 \mathrm{mg} \beta$-artemether and $120 \mathrm{mg}$ lumefantrine and three powders for oral suspension stability samples (Co-artesiane ${ }^{\circledR}$ ) containing $180 \mathrm{mg} \beta$-artemether and $1080 \mathrm{mg}$ lumefantrine were analysed using the validated fused-core HPLC method. For this, a homogenous FPP powder amount equivalent to $20.0 \mathrm{mg} \beta$-artemether and $120.0 \mathrm{mg}$ lumefantrine was accurately weighed and transferred to a $100.0 \mathrm{ml}$ volumetric flask. Eighty ml tetrahydrofuran was added, shaken for $5 \mathrm{~min}$ and diluted to volume using mobile phase. The mixture was filtered through $0.45 \mu \mathrm{m}$ HPLC syringe filters and analysed using HPLC.

\section{Preparation of stress solutions \\ Preparation of oxidative degradation of lumefantrine API solution}

Approximately $120.0 \mathrm{mg}$ lumefantrine API was accurately weighed and transferred into $100 \mathrm{ml}$ Erlenmeyer flask; $45.0 \mathrm{ml}$ tetrahydrofuran was added to ensure complete dissolution of lumefantrine and then $5.0 \mathrm{ml}$ $30 \%$ hydrogen peroxide was added. The solution was boiled for 120 min under constant reflux and analysed using HPLC.

\section{Preparation of acidic degradation of lumefantrine solution} Approximately $120.0 \mathrm{mg}$ of lumefantrine API was accurately weighed into $100 \mathrm{ml}$ Erlenmeyer flask; $10.0 \mathrm{ml}$ of $1 \mathrm{M}$ 
hydrochloric acid solution was added and incubated at $70^{\circ} \mathrm{C}$ for 30 hours. Subsequently, the solution was neutralized by addition of $2.0 \mathrm{ml}$ of $5 \mathrm{M}$ sodium hydroxide solution and then $38.0 \mathrm{ml}$ of THF was added. The mixture was sonicated for $5 \mathrm{~min}$, filtered and analysed.

\section{Preparation of heat stressed $\beta$-artemether API solution}

Preparation of heat stressed $\beta$-artemether was performed as described by De Spiegeleer et al. [20]. Briefly, approximately $20.0 \mathrm{mg}$ of $\beta$-artemether API was accurately weighed and transferred into a glass HPLC vial. The vial was put in a heating block at $145^{\circ} \mathrm{C}$ for $30 \mathrm{~min}$, resulting in approximately $70 \%$ conversion of $\beta$-artemether to related degradation products. Then $1.0 \mathrm{ml}$ tetrahydrofuran was added and the solution was quantitatively transferred to a $50.0 \mathrm{ml}$ volumetric flask by addition of $40 \mathrm{ml}$ tetrahydrofuran. The solution was then diluted to volume using mobile phase.

\section{Validation}

Linearity

A stock solution containing $250 \mu \mathrm{g} / \mathrm{ml} \beta$-artemether and $1,500 \mu \mathrm{g} / \mathrm{ml}$ lumefantrine in THF was prepared in triplicate. Different aliquots of these solutions were diluted in a dilution solvent consisting of THF/mobile phase (80:20 $\mathrm{V} / \mathrm{V})$ to five different concentrations, corresponding to $160,180,200,220$ and $240 \mu \mathrm{g} / \mathrm{ml}$ of $\beta$-artemether, and $960,1,080,1,200,1,320$ and $1,440 \mu \mathrm{g} / \mathrm{ml}$ of lumefantrine. Calibration curves for concentration versus peak area were plotted for each compound and the obtained data were subjected to linear regression analysis.

\section{Precision}

For intra-day precision, six sample solutions $(n=6)$ were prepared at $0.2 \mathrm{mg} / \mathrm{ml} \beta$-artemether and $1.2 \mathrm{mg} / \mathrm{ml}$ lumefantrine concentrations and analysed using HPLC. Similarly, the inter-day precision was evaluated in three consecutive days $(n=3 \times 6)$. $\beta$-artemether and lumefantrine concentrations were determined and relative standard deviations (RSD) were calculated.

\section{Accuracy (recovery test)}

Accuracy was tested by recovery experiments where $\beta$-artemether and lumefantrine reference solutions were added to a placebo sample at three levels: $75 \%$, $100 \%$ and $125 \%$ of the label claim. At each level, samples were prepared in duplicate and recovery percentage was calculated.

\section{Selectivity}

Selectivity of the method was evaluated by injecting the stressed $\beta$-artemether and lumefantrine solutions as well as reference standard solutions of $\alpha$-artemether, artemisinin, DHA and AHA. Moreover, UV-spectral purities of $\beta$-artemether and lumefantrine chromatographic peaks were evaluated using Waters' peak purity PDA evaluation.

\section{Robustness}

A Plackett-Burman experimental design consisting of 12 experiments with two replicates in block was used for the robustness testing (Modde version 8, Umetrics Inc, USA). Three sample solutions (stressed, test sample and reference solutions) were prepared at 100\% lc and analysed using different experimental conditions by varying different analytical parameters: flow $(0.8$, 1.0 , and $1.2 \mathrm{ml} / \mathrm{min}$ ), acetonitrile proportion $(50 \%, 52 \%$ and 54\%), mobile phase $\mathrm{pH}(2.8,3.0$ and 3.2$)$, and column temperature $\left(25^{\circ} \mathrm{C}, 30^{\circ} \mathrm{C}\right.$ and $\left.35^{\circ} \mathrm{C}\right) . \beta$-artemether and lumefantrine contents and different chromatographic characteristics were determined under each condition.

\section{Limit of detection (LoD) and limit of quantitation (LoQ)}

Combined standard solutions of $\beta$-artemether and lumefantrine were prepared by serial dilutions, ranging from 0.4 to $25 \mu \mathrm{g} / \mathrm{ml}$ for $\beta$-artemether and 0.2 to $11.5 \mu \mathrm{g} / \mathrm{ml}$ for lumefantrine, and injected onto the chromatographic system. The LoD was defined as the concentration for which a signal-to-noise ratio $(\mathrm{S} / \mathrm{N})$ of three was obtained and LoQ was considered to be the concentration at which $\mathrm{S} / \mathrm{N}$ was 10 .

\section{In-silico toxicological predictions}

In-silico toxicological study for lumefantrine and its related impurities was reported in previous publication [23]. Exhaustive impurity profiling of $\beta$-artemether (including its possible degradants) was also reported $[20,28]$. Therefore, to make in-silico toxicological comparative predictions for $\beta$-artemether and its identified related impurities, Derek Nexus v2.0 for Windows developed by Lhasa Ltd (Leeds, UK) was used. Derek Nexus ${ }^{\circledR}$ is an expert knowledge-based system, containing descriptions of molecular substructures which have been associated with toxic endpoints (structural alerts), that predicts a probability whether a chemical is toxic in humans, other mammals and bacteria. The program applies structure-activity relationships [(Q)SARs] and expert knowledge rules to derive a reasoned conclusion about the potential toxicity of the query chemical [29-31].

\section{Results}

\section{Development}

To develop a rapid, simple and stability-indicating isocratic HPLC method, three different fused-core stationary phases (Halo phenyl-hexyl, Halo C18 and Halo RP-Amide) and a mobile phase with different compositions of acetonitrile and $1 \mathrm{mM}$ phosphate buffer with varying $\mathrm{pH}$ (3.0, 5.0 and 7.0) were used. Relatively longer run time was obtained with $1 \mathrm{mM}$ phosphate buffer 
$\mathrm{pH} 7.0$ while $\mathrm{pH} 5.0$ resulted in poor peak shape for lumefantrine. At all conditions, there was no separation between $\beta$-artemether and lumefantrine using Halo phenyl-hexyl stationary phase. Using Halo $\mathrm{C}_{18}$ stationary phase column and a mobile phase composed of acetonitrile and $1 \mathrm{mM}$ phosphate buffer $\mathrm{pH} 3.0$, the retention factors obtained for $\beta$-artemether and lumefantrine were 11.8 and 3.0, respectively. Under these conditions, in spite of achieving good separation between $\beta$-artemether and lumefantrine, the peak shape of lumefantrine was found to be out of pharmacopoeial specifications (Ph Eur. specification $\mathrm{A}_{\mathrm{s}} \leq 1.5$ ) [27] and the total run time was relatively long, i e, $6 \mathrm{~min}$. Substituting the Halo $\mathrm{C}_{18}$ with a Halo RP-Amide stationary phase, different proportions of mobile phase solvents were evaluated (Table 1). The optimal mobile phase, composed of acetonitrile and $1 \mathrm{mM}$ phosphate buffer $\mathrm{pH}$ $3.0(52: 48, \mathrm{~V} / \mathrm{V})$, gave an adequate retention factor $k^{\prime}$ and lumefantrine peak shape $\left(\mathrm{A}_{\mathrm{s}}\right.$ 1.3) that complies with pharmacopoeial specifications within a short period of total run time of $4 \mathrm{~min}$ (Figure 2).

As indicated in the UV-spectra of Figure 2, $\beta$-artemether only shows reasonable UV-absorption at the lower wavelengths of the spectrum (200-230 nm), due to the absence of UV-chromophores in its structure. Thus, its quantification was performed at $210 \mathrm{~nm}$. For lumefantrine with a RT of $1.70 \mathrm{~min}$, quantification was performed at $335 \mathrm{~nm}$, the wavelength at which no UV-absorption interference from $\beta$-artemether was observed.

It was reported that the desbenzyl keto derivative (DBK) is the major degradation product after acidic degradation of lumefantrine, while the oxidative degradation of lumefantrine was reported to yield $\mathrm{N}$ oxide-lumefantrine [23]. Under the chromatographic conditions, DBK eluted before lumefantrine at retention time (RT) of $1.26 \mathrm{~min}$, while $\mathrm{N}$-oxide-lumefantrine was eluting after lumefantrine at RT of $3.17 \mathrm{~min}$ (see Additional file 1).

As indicated in Table 2, $\beta$-artemether and all its identified related impurities ( $\alpha$-artemether, DHA, artemisinin and AHA) were eluting at different RT without any interference with the main peak. Previous studies have indicated that AHA- $\beta$-artemether is the most critical pair to be separated [28], while other impurities like
DKA or furano acetate are sufficiently well separated from $\beta$-artemether. Moreover, lumefantrine and its related degradation impurities (DBK and the $\mathrm{N}$-oxide of lumefantrine) were also eluting at different RT. However, while some of $\beta$-artemether impurities (DHA, artemisinin and other degradation products from dry heat stress $\beta$-artemether) co-elute with lumefantrine, which however does not interfere with its assay due to negligible UV-absorption of these $\beta$-artemether impurities at $335 \mathrm{~nm}$, the $\mathrm{N}$-oxide-lumefantrine problematically coelutes with $\beta$-artemether peak, making selective quantification of $\beta$-artemether at $210 \mathrm{~nm}$ difficult. Therefore, the method quantifies lumefantrine separated from its related impurities at $335 \mathrm{~nm}$ (where $\beta$-artemether and its related impurities are not absorbing). Since lumefantrine and its related impurities have strong UV absorption at $210 \mathrm{~nm}$ and $\mathrm{N}$-oxide-lumefantrine is co-eluting with $\beta$-artemether, it is possible to selectively obtain the $\mathrm{UV}_{210 \mathrm{~nm}}$ peak area of $\beta$-artemether alone by back-calculating the peak area of $\mathrm{N}$-oxide-lumefantrine using the peak area conversion factor from $335 \mathrm{~nm}$ to $210 \mathrm{~nm}$ (i.e, 1.64) and subtracting the value from the co-eluting peak area at $210 \mathrm{~nm}$.

Therefore, compared to the method described in Ph. Int. [26], which uses conventional HPLC, the developed fusedcore method uses simple sample extraction technique and is isocratic, rapid, less costly and stability-indicating.

\section{Validation}

\section{Linearity}

Almost all the variation in peak area was explained by the linear concentration $(0.9997$ for $\beta$-artemether and 0.9997 for lumefantrine), indicating the linearity of the method in the assayed range ( 80 to $120 \%$ label claim). The regression analysis data are presented in Table 3.

\section{Precision}

In the prepared solutions for analysis, $100 \%$ label claim (lc) represents $0.2 \mathrm{mg} / \mathrm{ml} \beta$-artemether and $1.2 \mathrm{mg} / \mathrm{ml}$ lumefantrine solution.

\section{Intra-day precision}

Mean contents and RSD of $\beta$-artemether and lumefantrine in the intra-day precision analysis $(n=6)$ were $99.6 \%$ lc with RSD $=1.2 \%$ and $99.2 \%$ lc with $\mathrm{RSD}=0.5 \%$, respectively.

Table 1 Chromatographic parameters for $\beta$-artemether and lumefantrine at different mobile phase compositions using Halo RP-Amide stationary phase column

\begin{tabular}{|c|c|c|c|c|}
\hline $\begin{array}{l}\text { Mobile phase composition; Acetonitrile: } \\
1 \mathrm{mM} \text { phosphate buffer pH } 3.0\end{array}$ & $\begin{array}{l}\beta \text {-artemether } \\
\text { retention factor }\left(k^{\prime}\right)\end{array}$ & $\begin{array}{l}\beta \text {-artemether peak } \\
\text { symmetry factor }\left(A_{s}\right)\end{array}$ & $\begin{array}{l}\text { Lumefantrine } \\
\text { retention factor }\left(k^{\prime}\right)\end{array}$ & $\begin{array}{l}\text { Lumefantrine peak } \\
\text { symmetry factor }\left(A_{s}\right)\end{array}$ \\
\hline $54: 46$ & 5.5 & 1.0 & 1.5 & 1.4 \\
\hline $52: 48$ & 6.8 & 1.0 & 2.0 & 1.3 \\
\hline $50: 50$ & 7.5 & 1.0 & 2.8 & 1.8 \\
\hline
\end{tabular}

$t_{o}=0.4 \mathrm{~min}$. 


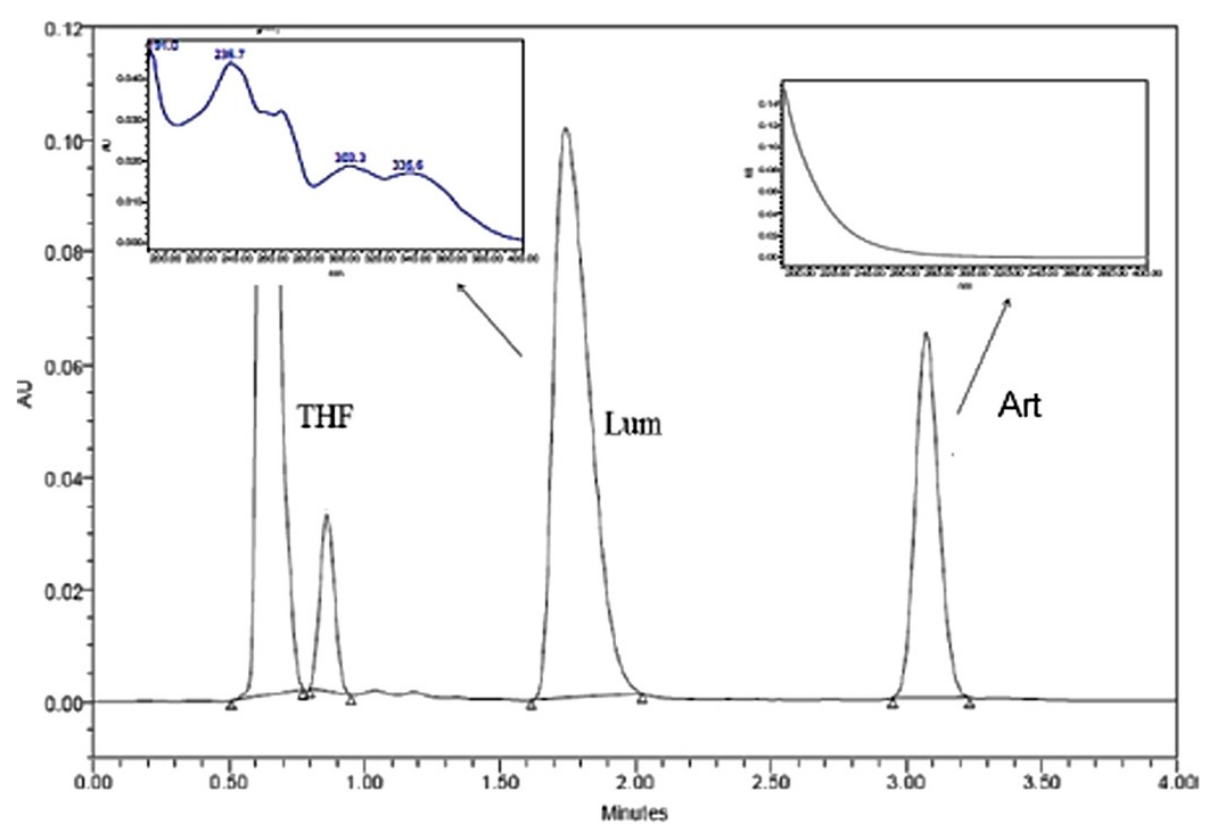

Figure 2 Typical chromatogram obtained on solution of $\beta$-artemether (Art) (RT: 3.07min) and lumefantrine (Lum) (RT: $1.70 \mathrm{~min}$ ) in tetrahydrofuran (THF) with their UV spectrum in the infronts.

\section{Inter-day precision}

Mean contents and RSD values of $\beta$-artemether and lumefantrine in the inter-day precision analysis $(n=3 \times 6)$ were $99.6 \%$ lc with $\mathrm{RSD}=1.1 \%$ and $99.4 \%$ lc with $\mathrm{RSD}=$ $0.6 \%)$, respectively.

For both compounds, the intra-day and inter-day precision \% RSD values were lower than $2.0 \%$, revealing precision of the method [32].

\section{Accuracy (recovery test)}

The recovery test was performed by analysing a spiked placebo. $\beta$-artemether mean recovery $(n=6)$ was $99.7 \%$ (RSD $=0.7 \%)$ and lumefantrine mean recovery was $99.7 \%$ $(\mathrm{RSD}=0.6 \%)$, indicating the accuracy of the method.

\section{Selectivity}

The chromatograms obtained with the stressed lumefantrine API solutions showed degradation impurity peaks separated from the main API peak, and similar findings were observed for the stressed $\beta$-artemether solutions. Acid-stressed lumefantrine resulted in DBK eluting before lumefantrine at RT of $1.26 \mathrm{~min}$, while oxidative stress resulted in $\mathrm{N}$-oxide-lumefantrine eluting after lumefantrine at RT of $3.17 \mathrm{~min}$. $\beta$-artemether and all its identified related impurities ( $\alpha$-artemether,
DHA, artemisinin and AHA) were eluting at different RT without any interference with the $\beta$-artemether peak. However, at $210 \mathrm{~nm}, \mathrm{~N}$-oxide-lumefantrine was co-eluting with $\beta$-artemether and some degradants of $\beta$-artemether were co-eluting with lumefantrine. There is no interference from $\beta$-artemether and its impurities for the estimation of lumefantrine and its related impurities at $335 \mathrm{~nm}$. Therefore, for the quantification of the two APIs, the method uses two wavelengths, $210 \mathrm{~nm}$ for $\beta$-artemether and $335 \mathrm{~nm}$ for lumefantrine.

The peak purity indices for both $\beta$-artemether and lumefantrine in different marketed FDC anti-malarial drug sample solutions determined with PDA detector under optimized chromatographic conditions indicated that the purity angle for both APIs was less than the purity threshold, revealing no significant excipient interference.

\section{Robustness}

A Plackett-Burman design was used to test the robustness of the method. Plackett-Burman design is a two level fractional factorial design where main effects are heavily confounded with two factor interactions. It is selected for robustness evaluation since it combines less experimentation with maximal information acquisition in the most efficient way.

Table 2 Retention time (RT) for $\boldsymbol{\beta}$-artemether and lumefantrine and their related impurities

\begin{tabular}{lcccccccc}
\hline$\#$ & $\boldsymbol{\beta}$-artemether & DHA & Artemisinin & a-artemether & AHA & Lumefantrine & DBK & N-oxide of lumefantrine \\
\hline RT $(\min )$ & 3.07 & 1.62 & 1.68 & 2.14 & 2.71 & 1.70 & 1.26 & 3.17 \\
\hline
\end{tabular}


Table 3 Calibration curve for $\beta$-artemether and lumefantrine

\begin{tabular}{lll}
\hline Regression parameters & $\boldsymbol{\beta}$-artemether & Lumefantrine \\
\hline Regression coefficient, $\mathrm{R}^{2}$ & 0.9997 & 0.9997 \\
\hline Slope \pm standard error & $103.1 \pm 1.1$ & $4880.8 \pm 51.8$ \\
\hline Intercept \pm standard error & $1708.1 \pm 235.7$ & $224820.8 \pm 62658.3$ \\
\hline Relative standard error $(\%)$ & 1.1 & 1.1 \\
\hline Concentration range $(\mu \mathrm{g} / \mathrm{ml})$ & $160-240$ & $960-1440$ \\
\hline F-value & 8060.4 & 8876.5 \\
\hline Number of points & 5 & 5 \\
\hline
\end{tabular}

Four factors, with deliberate small deviations from the method settings, were considered: percentage $\mathrm{V} / \mathrm{V}$ of acetonitrile in mobile phase (from 50 to 54\%), flow (from 0.8 to $1.2 \mathrm{ml} / \mathrm{min}$ ), $\mathrm{pH}$ (from 2.8 to 3.2 ) and column temperature (from 25 to $35^{\circ} \mathrm{C}$ ) (see Additional file 1).

Mobile phase $\mathrm{pH}$ significantly affects the peak shape of lumefantrine while it did not reveal prominent influence on that of $\beta$-artemether. Thus, lumefantrine peak symmetry was selected as a critical quality parameter for the robustness test. The final method provided lumefantrine peak shape $\left(A_{s}\right.$ 1.3) that complies with pharmacopoeial specifications. Moreover, even the deliberate method variations provided better lumefantrine peak shapes $\left(\mathrm{A}_{\mathrm{s}} 1.4\right.$ and
1.8) (Table 1) than the very tailed lumefantrine peak shape $\left(A_{s} 2.1\right)$ reported in the literature [23]. In the stressed sample solutions, there was no difference in selectivity between the results of the method setting and the deliberate variations of both $\beta$-artemether and lumefantrine APIs and their respective degradation products.

Typical contour plots for different chromatographic parameters as a function of operational variables levels is presented in Figure 3. Figure $3(\mathrm{a}, \mathrm{b}$ and $\mathrm{c}$ ) is the visual representation of sensitivity, i.e. how quantitatively acetonitrile proportion (\%ACN), flow rate and temperature influence the retention factor $\left(k^{\prime}\right)$. Moreover, it is revealed in the Figure 3 that small deviations from the method setting introduced in the four parameters do not affect $\mathrm{A}_{\mathrm{s}}$ and $k^{\prime}$-specifications set in Ph. Eur. [27]. The observed effects for peak symmetry $\left(\mathrm{A}_{\mathrm{s}}\right)$ of lumefantrine and $k^{\prime}$ for $\beta$-artemether and lumefantrine are presented in Figure 4. Flow rate and \%ACN have more pronounced effect on ' $k$ ' of both compounds while lumefantrine peak shape was more affected by $\% \mathrm{ACN}$.

The mean content of $\beta$-artemether and lumefantrine was found to be $100.9 \% \mathrm{lc} \pm 1.0$ (RSD 1.0\%) and $99.7 \%$ lc \pm 0.4 (RSD 0.4\%), respectively (see Additional file 1 ). Therefore, the deliberate changes from the method settings in chromatographic conditions $(\% \mathrm{~V} / \mathrm{V}$ of acetonitrile (a)

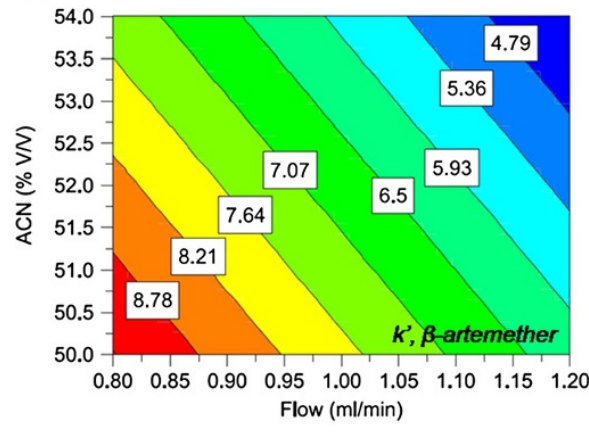

(c)

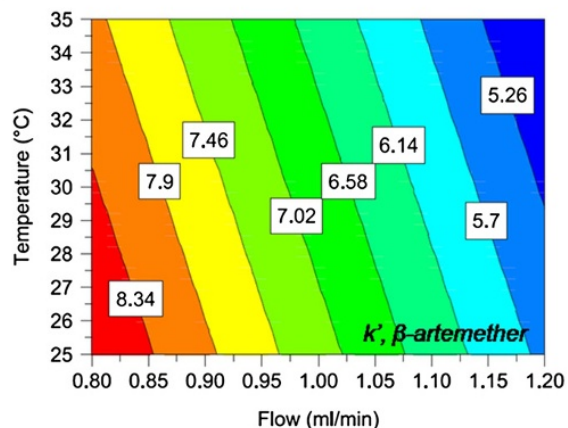

(b)

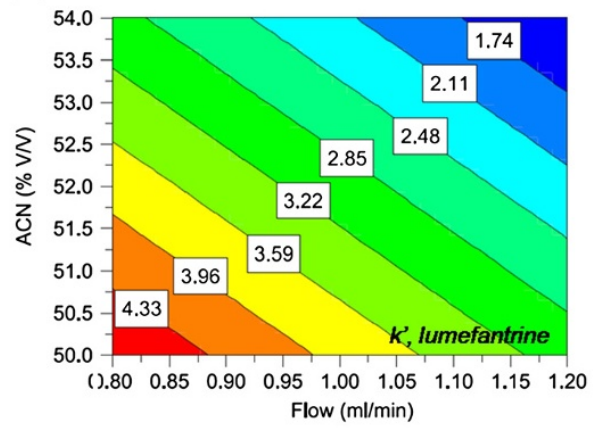

(d)

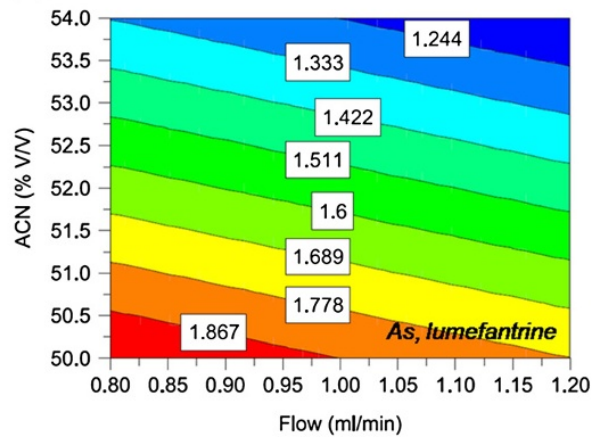

Figure 3 Contour plots: (a) Acetonitrile (ACN) (\% V/V) vs flow (ml/min) for retention factor ( $k$ ) of $\beta$-artemether; (b) ACN (\% V/V) vs flow (ml/min) for $k^{\prime}$ of lumefantrine; (c) temperature $\left({ }^{\circ} \mathrm{C}\right)$ vs flow (ml/min) for $k^{\prime}$ of $\beta$-artemether; (d) ACN (\% V/V) vs flow (ml/min) for $A_{s}$ of lumefantrine. For (a), (b) and (d) mobile phase: $\mathrm{pH}$ 3, column temperature: $30^{\circ} \mathrm{C}$ and for (c) \% ACN: 52 , mobile phase: $\mathrm{pH} 3$. 


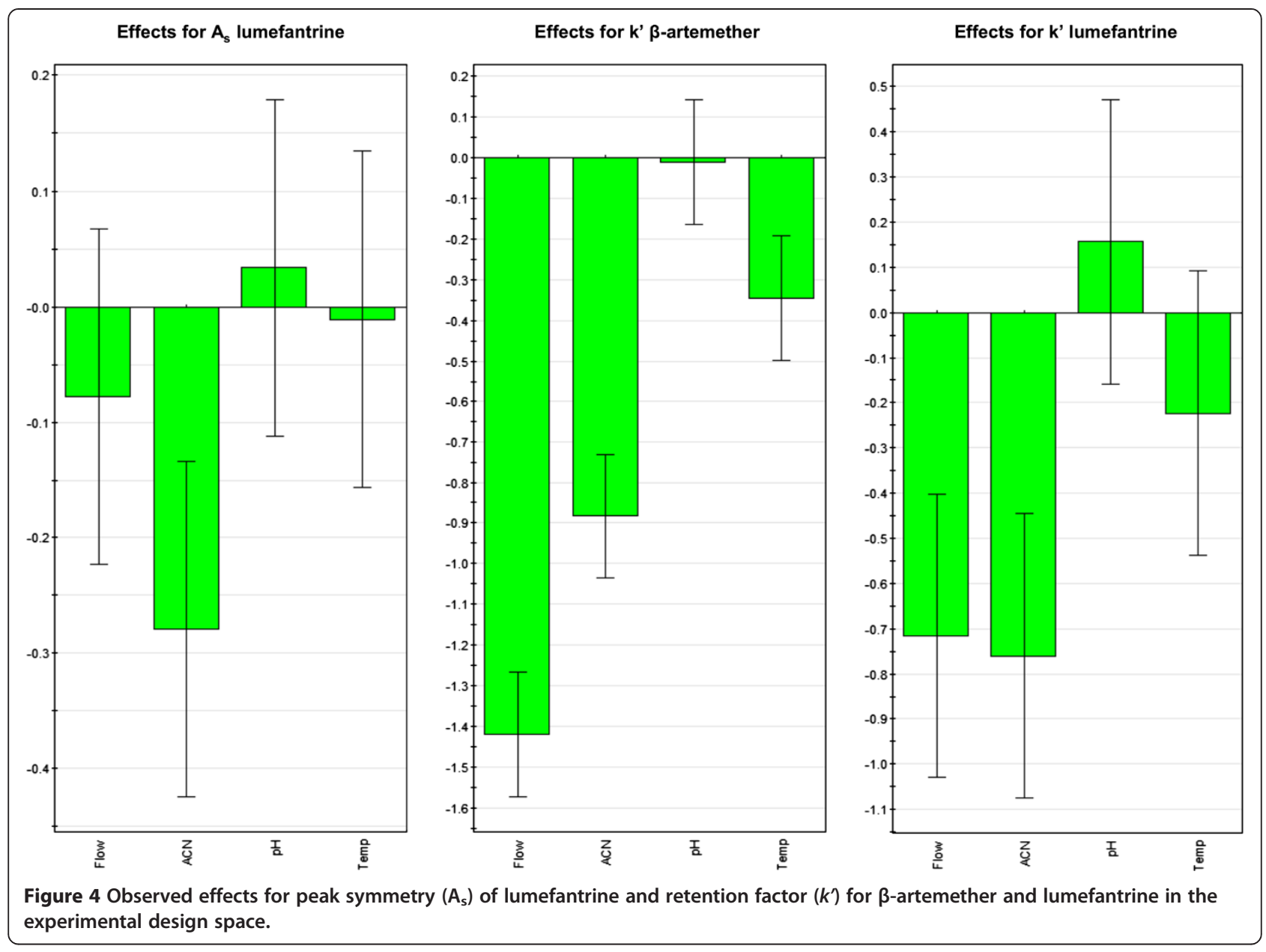

in mobile phase (from 50 to 54\%), flow (from 0.8 to $1.2 \mathrm{ml} / \mathrm{min}$ ), $\mathrm{pH}$ (from 2.8 to 3.2 ) and column temperature (from 25 to $35^{\circ} \mathrm{C}$ )) have little impact on the assay of $\beta$-artemether and lumefantrine containing anti-malarial FDC products indicating the robustness of the method.

\section{Limit of detection (LoD) and limit of quantitation (LoQ)}

According to the determined signal-to-noise ratio, the LoD and LoQ for $\beta$-artemether were calculated to be 3.4 $\mu \mathrm{g} / \mathrm{ml}$ and $10.0 \mu \mathrm{g} / \mathrm{ml}$, respectively. For lumefantrine, LoD was $0.1 \mu \mathrm{g} / \mathrm{ml}$ and its LoQ was $0.4 \mu \mathrm{g} / \mathrm{ml}$. As the purpose of this developed method is to quantitatively determine both $\beta$-artemether and lumefantrine simultaneously in FDC anti-malarial products where the compounds exist in the mass ratio $\beta$-artemether: lumefantrine of $1: 6$, the LoD and LoQ values obtained for $\beta$-artemether should be considered as the overall detection and quantification limits, while for lumefantrine, the risk of overloading the HPLC system is to be considered. Both opposing aspects are solved with the proposed method.

\section{Analysis of marketed FDC products}

The results of real sample analysis are presented in Table 4. All the analysed batches presented $\beta$-artemether and lumefantrine contents complying with the 95$105 \%$ lc specifications. The $\beta$-artemether content in the tablet samples varied from $98.2 \%$ to $103.2 \%$ while lumefantrine content varied from $97.9 \%$ to $101.5 \%$. In

Table 4 Contents of $\beta$-artemether and lumefantrine in fixed dose combination (FDC) products $(n=6)$

\begin{tabular}{|c|c|c|c|}
\hline \multirow[t]{2}{*}{ FDC samples } & \multirow{2}{*}{$\begin{array}{l}\text { Batch/Lot } \\
\text { No. }\end{array}$} & \multicolumn{2}{|c|}{ Content $(\%) \pm$ S.D. } \\
\hline & & $\beta$-artemether & Lumefantrine \\
\hline \multirow[t]{2}{*}{ Artemine ${ }^{\circledR}$ tablets } & A & $103.2 \pm 1.5$ & $101.5 \pm 0.9$ \\
\hline & $B$ & $102.2 \pm 1.7$ & $101.3 \pm 0.5$ \\
\hline \multirow[t]{2}{*}{ Coartem $^{\circledR}$ tablets } & A & $98.2 \pm 0.9$ & $97.92 \pm 0.7$ \\
\hline & B & $99.2 \pm 1.5$ & $98.8 \pm 0.7$ \\
\hline \multirow{3}{*}{$\begin{array}{l}\text { Co-Artesiane powder for oral } \\
\text { suspension }\end{array}$} & A & $100.9 \pm 1.9$ & $101.4 \pm 0.9$ \\
\hline & $\mathrm{B}$ & $99.7 \pm 1.6$ & $102.0 \pm 0.8$ \\
\hline & $\bar{C}$ & $101.1 \pm 1.3$ & $100.8 \pm 0.8$ \\
\hline
\end{tabular}

S.D. $=$ standard deviation. 


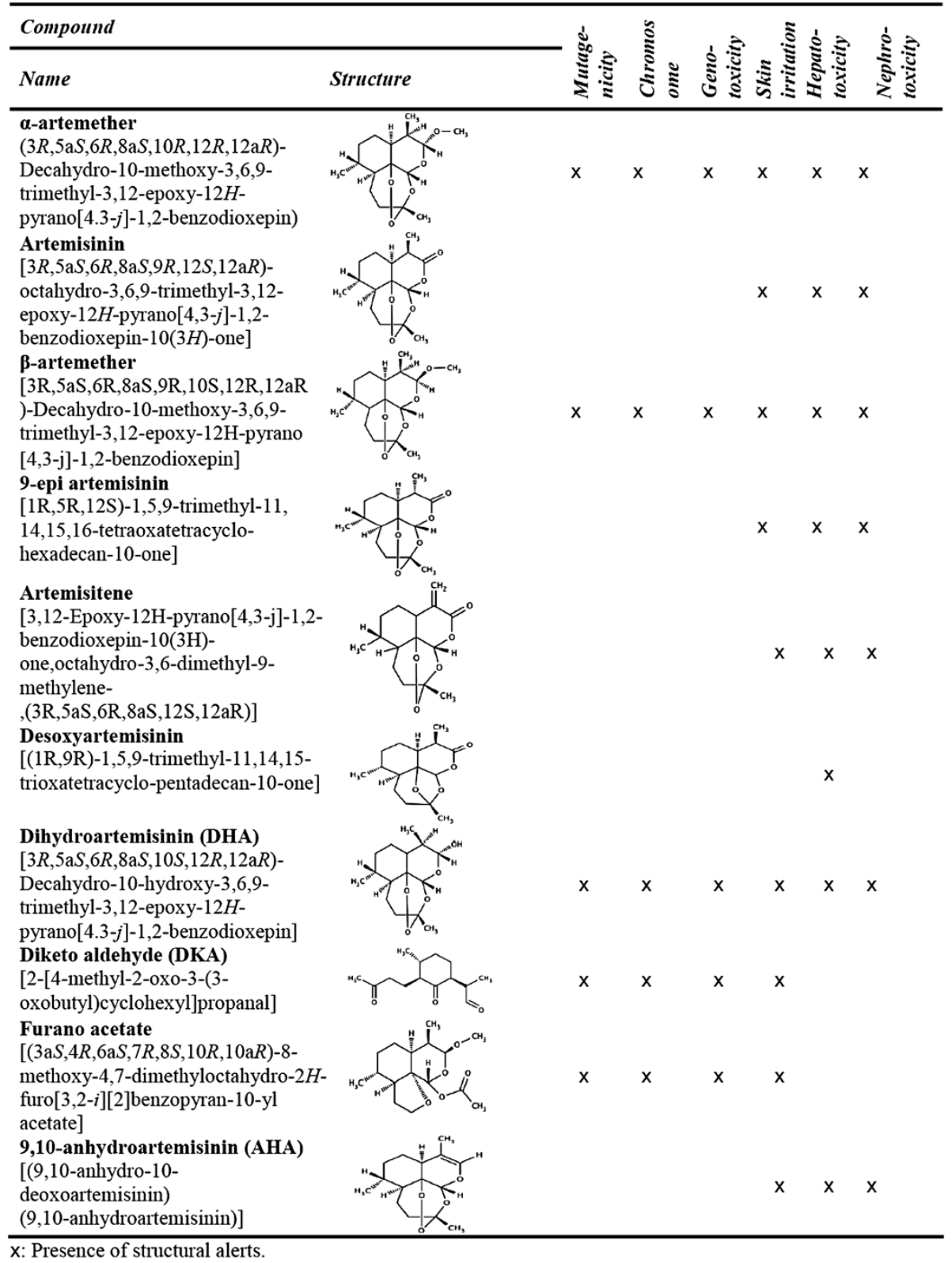

Figure 5 In-silico toxicity profile of $\beta$-artemether and its impurities.

Co-Artesiane powder for oral suspension FDC product, $\beta$-artemether content was in the range of $99.7 \%$ to $101.1 \%$ while that of lumefantrine was ranging from $100.8 \%$ to $102.0 \%$.

\section{In-silico toxicological predictions of $\beta$-artemether and its related impurities}

In-silico toxicity profile of lumefantrine and its related impurities was reported in previous publication [23]. In this study, mutagenicity, chromosome abrasion, genotoxicity, skin irritation, hepatotoxicity and nephrotoxicity endpoints for $\beta$-artemether, as well as for its related observed and already described impurities, have been investigated using Derek Nexus ${ }^{\circledR}$ and the result is presented in Figure 5 . The toxicity profile of $\beta$-artemether and all its identified related degradants and synthetic impurities is defined by several general toxicity alerts. DHA, $\alpha$-artemether and $\beta$-artemether were found to have toxicity endpoints for mutagenicity, chromosomal abrasion, genotoxicity, skin irritation, hepatogenicity and nephrotoxicity. $\beta$-artemether and all its identified related impurities, except desoxyartemisinin which has structural alert for hepatotoxicity, have substructures for skin irritation. Derek Nexus ${ }^{\circledR}$ did not trigger mutagenicity, chromosomal abrasion 
and genotoxicity for artemisinin, 9-epi artemisinin, artemisitene, desoxyartemisinin and AHA.

\section{Discussion}

The development of rapid, economical and reliable stability-indicating methods is essential to assure the quality of anti-malarial drugs in general, and the $\beta$ artemether-lumefantrine FDC anti-malarial products in particular. The use of poor quality drugs might contribute to the development of resistance in endemic areas due to the exposition to subtherapeutic doses [19]. The quality control of the anti-malarial pharmaceutical preparations currently on the market might help to assure the efficacy of the treatment and avoid resistance to these anti-malarial drugs.

A simple, rapid and economical stability-indicating, fused-core HPLC method has been developed and validated for the routine quality control tests of $\beta$-artemether and lumefantrine in FDC anti-malarial products. The method uses a simple sample preparation procedure (extraction of the APIs with tetrahydrofuran) and is rapid with a total run time of only four minutes. The results of stress testing show that the developed assay method is selective and stability-indicating as it is capable of separating both $\beta$-artemether and lumefantrine from their respective degradation products. Moreover, the developed method was successfully applied to quantitatively analyse $\beta$-artemether and lumefantrine in marketed FDC anti-malarial drugs.

Safety of a drug product is dependent not only on the toxicological properties of the active drug substance, but also on the toxicological properties of its impurities including the possible degradants. Impurity profiling of both $\beta$-artemether and lumefantrine as well as in-silico toxicity profile of lumefantrine and its related impurities have been reported in previous publications [20,23,28]. Here, in-silico toxicological profile of $\beta$-artemether was compared against its related identified impurities using Derek Nexus ${ }^{\circledR}$. Derek Nexus ${ }^{\circledR}$ is a computer-based expert system for the qualitative prediction of possible toxic action of compounds on the basis of their chemical structure. The system is able to perceive chemical substructures within molecules and relate these to a rule-base, linking the substructures with likely types of toxicity [31]. The toxicity profile of $\beta$-artemether and all its identified related degradants and synthetic impurities is defined by several general toxicity alerts for mutagenicity, chromosomal abrasion, genotoxicity, skin irritation, hepatotoxicity and nephrotoxicity. However, no significant difference in in-silico toxicity profile between $\beta$-artemether and its related impurities is observed, which is also consistent with experimentally obtained Ames mutagenicity results [20].

\section{Conclusions}

A stability-indicating HPLC method for simultaneous assay of $\beta$-artemether and lumefantrine fixed dose combination anti-malarial products was developed, using a fused-core reversed-phase amide stationary phase combined with an isocratic acetonitrile sodium phosphate mobile phase [Acetonitrile/1 mM phosphate buffer $\mathrm{pH} 3.0$ $(52: 48, \mathrm{v} / \mathrm{v})]$. It is a rapid (four minutes total run time), precise and accurate method that can be utilized to quantify these anti-malarials in the presence of their related degradation products or impurities produced during inadequate transportation and storage. This method can be applied in the routine regulatory quality control of $\beta$-artemether and lumefantrine containing FDC drug products. The in-silico toxicological investigation using Derek Nexus ${ }^{\circledR}$ indicated overall a toxicity risk for $\beta$-artemether-related impurities comparable to that of the API $\beta$-artemether itself.

\section{Additional file}

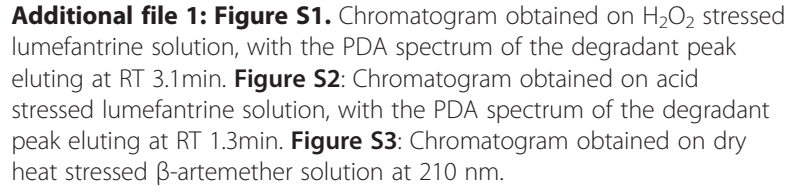

Additional file 1: Figure S1. Chromatogram obtained on $\mathrm{H}_{2} \mathrm{O}_{2}$ stressed lumefantrine solution, with the PDA spectrum of the degradant peak eluting at RT $3.1 \mathrm{~min}$. Figure S2: Chromatogram obtained on acid stressed lumefantrine solution, with the PDA spectrum of the degradant peak eluting at RT 1.3min. Figure S3: Chromatogram obtained on dry heat stressed $\beta$-artemether solution at $210 \mathrm{~nm}$.

\section{Competing interests}

The authors declare that they have no competing interests.

\section{Authors' contributions}

SS executed the analytical laboratory experiments and, together with $\mathrm{KV}$, wrote the manuscript. KV, MD and NB performed part of the analytical experiments and the in-silico toxicity evaluation. EW performed the statistical data analysis. LD, KP and $\mathrm{CB}$ critically reviewed this manuscript. BDS was the overall study director, responsible for experimental design, interpretation of data and review of the manuscript. All authors read and approved the final manuscript.

\section{Acknowledgements}

The authors would like to thank Dafra Pharmaceuticals (Turnhout, Belgium) for the provision of the reference substances. SS is supported by the Infectious Diseases and Epidemiology Project within Institutional University Cooperation Programme (Jimma University) of VLIR. KV and MD are supported by the Institute for the Promotion of Innovation through Science and Technology in Flanders (IWT-Vlaanderen) (Nos. 110533 and 101529), while EW and BDS are supported by the Special Research Fund of Ghent University (Grant number BOF 01J22510).

\section{Author details}

${ }^{1}$ Drug Quality and Registration (DruQuaR) group, Faculty of Pharmaceutical Sciences, Ghent University, Harelbekestraat 72, Ghent B-9000, Belgium.

${ }^{2}$ School of Pharmacy, Jimma University, P.O. Box 378, Jimma, Ethiopia. ${ }^{3}$ Department of Medical Imaging, Physiology and Biometrics, Faculty of Veterinary Medicine, Ghent University, Salisburylaan 133, Merelbeke B-9820, Belgium.

Received: 20 February 2013 Accepted: 12 April 2013 Published: 30 April 2013

\section{References}

1. WHO: World Malaria Report, Global Malaria Programme. Geneva: World Health Organization Publication; 2008. http://whqlibdoc.who.int/ publications/2008/9789241563697_eng.pdf [Accessed on June 22, 2012 at 18:50] 
2. WHO: World Malaria Report, Global Malaria Programme. Geneva: World Health Organization Publication; 2011. http://www.who.int/malaria/ world_malaria_report_2011/en/ [Accessed on June 22, 2012 at 19:10].

3. Murray CJ, Rosenfeld LC, Lim SS, Andrews KG, Foreman KJ, Haring D, Fullman N, Naghavi M, Lozano R, Lopez AD: Global malaria mortality between 1980 and 2010: a systematic analysis. Lancet 2012, 379:413.

4. WHO: Guidelines for the treatment of malaria. Geneva: World Health Organization; 2010.

5. Ashley EA, White NJ: Artemisinin-based combinations. Cur Opin Infect Dis 2005, 18:531-36.

6. Gilles HM, Warrell DA: Essential Malariology. London: Arnold Publishers; 1993:p188.

7. Dondorp AM, Nosten F, Yi P, Das D, Phyo AP, Tarning J, Lwin KM, Ariey F, Hanpithakpong W, Lee SJ, Ringwald P, Silamut K, Imwong M, Chotivanich K, Lim P, Herdman T, Yeung AS, Singhasivanon P, Day PJ, Lindegardh N, Socheat D, White NJ: Artemisinin resistance Plasmodium falciparum malaria. N Engl J Med 2009, 361:455-467.

8. Roper C, Pearce R, Nair S, Sharp B, Nosten F, Anderson T: Intercontinental spread of pyrimethamine-resistant malaria. Science 2004, 305:1124.

9. Kaur H, Green MD, Hostetler DM, Fernández FM, Newton PN: Anti-malarial drug quality: methods to detect suspect drugs, A Review. Therapy 2010, 7:49-57.

10. WHO: Counterfeit medicines. Fact sheet No. 275. 1211 Geneva 27 Switzerland: WHO Media Center; 2006. [http://whqlibdoc.who.int/fact_sheet/2006/ FS_275.pdf] [Accessed on 15 June 2012 at 11:30

11. WHO: Drug policy. [www.searo.who.int/EN/Section10/Section21/ Section340_4040.htm] [Accessed on 16 June 2012 at 10:25].

12. $\mathrm{ICH}$ guidelines - International Conference on Harmonization, Q1A(R2: Stability testing of new drug substances and products CPMP//CH/2736/99; 2003. [http:// www.ema.europa.eu/docs/en_GB/document_library/Scientific_guideline/2009/ 09/WC500002651.pdf], [Accessed on 19 June 2012 at 19:35].

13. Hamid K, Mushir A, Alka A, Javed A: Stability testing of pharmaceutical products - comparison of stability testing guidelines. Cur Pharm Anal 2010, 6:142-150.

14. Baert B, De Spiegeleer B: Quality analytics of internet pharmaceuticals. Anal Bioanal Chem 2010, 398:125-136.

15. Martindale: The complete drug reference. 36th edition. Lambeth High Street, London: Pharmaceutical press; 2009:598-599.

16. The Merck Index. 13th edition. USA: Merck \& Co., Inc; 2001

17. Health Canada/Health Products and Food Branch Inspectorate: Guidelines for Temperature Control of Drug Products during Storage and Transportation (GUI-0069); 2012. http://infitrak.com/ims/wp-content/uploads/GUI-0069-eng. pdf, [Accessed on 19 June 2012 at 23:10].

18. Cesar ID, Pianetti GA: Quantitation of artemether in pharmaceutical raw material and injections by high performance liquid chromatography. Braz J Pharm Sci 2009, 45:737-742.

19. Magnus A, Atemnkeng Katelijne De C, Jacqueline Plaizier V: Quality control of active ingredients in artemisinin-derivative anti-malarials within Kenya and DR Congo. Trop Med Int Health 2001, 6:980-982.

20. De Spiegeleer BMJ, D'Hondt M, Vangheluwe E, Vandercruyssen $\mathrm{K}$, De Spiegeleer BVI, Jansen H, Ilse K, Van Gompel J: Relative response factor determination of $\beta$-artemether degradants by a dry heat stress approach. J Pharm Biomed Anal 2012, 70:111-116.

21. Cesar ID, Nogueira FHA, Pianetti GA: Comparison of HPLC, UV spectrophotometry and potentiometric titration methods for the determination of lumefantrine in pharmaceutical products. J Pharm Biomed Anal 2008, 48:223-226.

22. Patil KR, Rane VP, Sangshetti JN, Shinde DB: A stability-indicating Ic method for lumefantrine. Chromatographia 2009, 69:375-379.

23. Verbeken M, Suleman S, Baert B, Vangheluwe E, Van Dorpe S, Burvenich C, Duchateau L, Jansen FH, De Spiegeleer B: Stability-indicating HPLC-DAD/UVESI/MS impurity profiling of the anti-malarial drug lumefantrine. Malar J 2011, 10:51

24. Cesar ID, Nogueira FHA, Pianetti GA: Simultaneous determination of artemether and lumefantrine in fixed dose combination tablets by HPLC with UV detection. J Pharm Biomed Anal 2008, 48:951-954

25. Authorized Lumefantrine and Artemether Tablets USP Salmous Standard. 2009. [http://www.usp.org/sites/default/files/usp_pdf/EN/nonUSStandards/ lumefantrineArtemetherTablets.pdf], [Accessed on 19/06/2012 at 19:30].

26. WHO: International Pharmacopoeia. 4th edition. Geneva: World Health Organization; 2008
27. European Directorate for the Quality of Medicines: European Pharmacopoeia. 5th edition. Strasbourg: EDQM; 2006.

28. Vandercruyssen $K$, D'Hondt M, Vergote $V$, Jansen H, Burvenich C, De Spiegeleer B: LC-UV/MS quality analytics of paediatric artemether formulations. J Pharm Anal 2013. Manuscript accepted for publication

29. Ellison CM, Madden JC, Judson P, Cronin MTD: Using in-silico tools in a weight of evidence approach to aid toxicological assessment. Mol Inf 2010, 29:97-110.

30. Mohan CG, Gandhi T, Garg D, Shinde R: Computer-assisted methods in chemical toxicity prediction. Mini Rev Med Chem 2007, 7:499-507.

31. Sanderson DM, Earnshaw CG: Computer Prediction of Possible Toxic Action from Chemical Structure; The DEREK System. Hum Exp Toxicol 1991, 10:261-273.

32. Shabir GA: Validation of high-performance liquid chromatography methods for pharmaceutical analysis. Understanding the differences and similarities between validation requirements of the US Food and Drug Administration, the US Pharmacopeia and the International Conference on Harmonization. J Chromatogr A 2003, 987:57-66.

doi:10.1186/1475-2875-12-145

Cite this article as: Suleman et al: A rapid stability-indicating, fused-core HPLC method for simultaneous determination of $\beta$-artemether and lumefantrine in anti-malarial fixed dose combination products. Malaria Journal 2013 12:145.

\section{Submit your next manuscript to BioMed Central and take full advantage of:}

- Convenient online submission

- Thorough peer review

- No space constraints or color figure charges

- Immediate publication on acceptance

- Inclusion in PubMed, CAS, Scopus and Google Scholar

- Research which is freely available for redistribution

Submit your manuscript at www.biomedcentral.com/submit
C Biomed Central 